\title{
Graduating 4th year radiology residents' perception of optimal imaging modalities for neoplasm and trauma: a pilot study from four U.S. universities*
}

Percepção de médicos residentes em radiologia de $4^{\circ}$ ano sobre as melhores modalidades de imagem na investigação de neoplasias e trauma: um estudo piloto de quatro universidades americanas

\author{
Jorge Elias Junior ${ }^{1}$, Richard C. Semelka ${ }^{2}$, Ersan Altun ${ }^{3}$, N. Cem Balci ${ }^{4}$, Sarah L. Thomas ${ }^{5}$, \\ Shahid M. Hussain ${ }^{6}$, Diego R. Martin ${ }^{7}$
}

\begin{abstract}
Objective: Our purpose was to assess 4th year radiology residents' perception of the optimal imaging modality to investigate neoplasm and trauma. Materials and Methods: Twenty-seven 4th year radiology residents from four residency programs were surveyed. They were asked about the best imaging modality to evaluate the brain and spine, lungs, abdomen, and the musculoskeletal system. Imaging modalities available were MRI, CT, ultrasound, PET, and Xray. All findings were compared to the ACR appropriateness criteria. Results: MRI was chosen as the best imaging modality to evaluate brain, spine, abdominal, and musculoskeletal neoplasm in $96.3 \%, 100 \%, 70.4 \%$, and $63 \%$ of residents, respectively. CT was chosen by $88.9 \%$ to evaluate neoplasm of the lung. Optimal imaging modality to evaluate trauma was CT for brain injuries (100\%), spine (92.6\%), lung (96.3\%), abdomen (92.6\%), and major musculoskeletal trauma (74.1\%); MRI was chosen for sports injury (96.3\%). There was agreement with ACR appropriateness criteria. Conclusion: Residents' perception of the best imaging modalities for neoplasm and trauma concurred with the appropriateness criteria by the ACR.
\end{abstract}

Keywords: Resident education; Medical education; Imaging modalities.

Resumo Objetivo: Avaliar a percepção de médicos residentes em radiologia de $4^{\circ}$ ano sobre as melhores modalidades de imagem na investigação de neoplasias e trauma. Materiais e Métodos: Vinte e sete médicos residentes de $4^{\circ}$ ano de quatro programas de residência em radiologia americanos participaram do estudo. Aos participantes foi perguntado sobre a melhor modalidade de imagem para se avaliar o cérebro e a coluna vertebral, pulmões, abdome e o sistema musculoesquelético. As modalidades de imagem disponíveis foram: RM, TC, ultrassonografia, PET e radiografia simples. Todos os achados foram comparados com os Critérios de Adequação de Exames de Imagem e Radioterapia do ACR. Resultados: A RM foi escolhida como melhor modalidade de imagem para se avaliar neoplasias encefálicas, espinhais, abdominais e musculoesqueléticas por $96,3 \%, 100 \%, 70,4 \%$ e $63 \%$ dos residentes, respectivamente. A TC foi escolhida por $88,9 \%$ dos residentes para avaliar neoplasias pulmonares. A modalidade de imagem ótima para se avaliar trauma foi a TC para lesões encefálicas (100\%), espinhais (92,6\%), pulmonares (96,3\%), abdominais (92,6\%) e grandes lesões traumáticas musculoesqueléticas (74,1\%); a RM foi escolhida para lesões esportivas (96,3\%). Observou-se concordância com os critérios de adequação do ACR. Conclusão: Houve concordância entre a percepção dos residentes sobre as melhores modalidades de imagem para avaliação de neoplasias e trauma e os critérios de adequação do ACR.

Unitermos: Formação de residentes; Educação médica; Modalidades de imagem.

Elias Jr J, Semelka RC, Altun E, Balci NC, Thomas SL, Hussain SM, Martin DR. Graduating 4th year radiology residents' perception of optimal imaging modalities for neoplasm and trauma: a pilot study from four U.S. universities. Radiol Bras. 2011 Set/Out;44(5):283288.

* Study developed at University of North Carolina at Chapel Hill, Chapel Hill, NC, USA.

1. MD, PhD, Professor of Radiology, School of Medicine of Ribeirão Preto, University of São Paulo, Ribeirão Preto, SP, Brazil. 2. MD, Professor of Radiology, Department of Radiology, University of North Carolina at Chapel Hill, Chapel Hill, NC, USA.

3. MD, International Scholar, Department of Radiology, University of North Carolina at Chapel Hill, Chapel Hill, NC, USA.

4. MD, Professor of Radiology, Department of Radiology, Saint Louis University, St. Louis, MO, USA.

5. MD, Resident Physician, Department of Radiology, University of North Carolina at Chapel Hill, Chapel Hill, NC, USA.
6. MD, Professor of Radiology, Department of Radiology, University of Nebraska Medical Center, Omaha, NE, USA.

7. MD, PhD, Professor of Radiology, Department of Radiology, Emory University School of Medicine, Atlanta, GA, USA.

Corresponding author: Richard C. Semelka, M.D. Department of Radiology, University of North Carolina at Chapel Hill. CB\# 7510101 Manning Drive, Chapel Hill, North Carolina 275997510. Email: richsem@med.unc.edu

Received August 3, 2011. Accepted after revision September 8, 2011.

\section{INTRODUCTION}

The specialty of Radiology has embraced the importance of practice guidelines to guide performance of imaging studies ${ }^{(1)}$. Various agencies and societies have described appropriateness criteria or guidelines regarding imaging modality usage for various clinical problems ${ }^{(2,3)}$. All guidelines 
acknowledge that multiple factors contribute in decision-making for the selection of appropriate imaging modality under specific clinical conditions. The ACR Appropriateness Criteria ${ }^{\circledR}$ committee states: "The complexity and severity of a patient's clinical condition dictates the selection of appropriate imaging procedures and treatments... The availability of equipment or personnel may influence the selection of appropriate imaging procedures or treatments...The ultimate decision regarding the appropriateness of any specific radiologic examination or treatment must be made by the referring physician and radiologist in light of all the circumstances presented in an individual situation"(4).

The decision-making process for selection of an appropriate imaging modality includes the determination of: 1) how consistently the procedure displays disease processes, and 2) how consistently it shows good image quality, 3) how safe the procedure is, 4) how sufficient the training and expertise for the application and interpretation of the procedure is, 5) how the procedure affects the outcome for the patient, and 6) how the procedure affects the costbenefit analysis.

Learning these evaluations is one of the main missions of a radiology resident training program and will influence the way healthcare evolves. It has been shown that hospital size, academic institution affiliation, and geography affect radiology resident training ${ }^{(5)}$.

The purpose of this pilot study was to assess and compare the perception of the graduating fourth year residents from four universities as to the optimal method to investigate for neoplasm and trauma with imaging modalities.

\section{MATERIALS AND METHODS}

All graduating fourth-year residents from four university residency programs in Radiology were surveyed: Univ A $(n=6)$, Univ B ( $=5)$, Univ C $(\mathrm{n}=2)$, and Univ $D(n=14)$. Institutions were selected based on their common concern about this subject. All programs provided their residents adequate exposure to the equipment and technology of the surveyed modalities. We specifically targeted only graduating 4th year residents, as this was the in-training group that would have the most knowledge both from the literature and from the institution at which they are training.

Surveys were administered in hard copy form in person by the residency program coordinator in July of 2006. All residents returned the anonymously filled-out forms to the same person by end of September 2006.

The main survey question was: "Based on your experience at your institution and your reading of the literature, which is the best test to investigate each of the listed disease processes by organ system? If the answer is more than one, check more than one, but attempt to answer with just one response in each category". The residents were surveyed for what their choices were for the best imaging modality to evaluate the brain and spine, lungs, abdomen (general), liver, pancreas, kidneys, and the musculoskeletal system giving a specific clinical setting of neoplasm or trauma. Neoplasm includes all benign and malignant tumors. Trauma was considered as one category for each region, except for the musculoskeletal system where it was separated into sports injury and major trauma. The imaging modalities available to residents were magnetic resonance imaging (MRI), computerized tomography (CT), ultrasound, positron emission tomography (PET) and X-ray. Modalities were then considered the "single best test" if only that modality was checked off on the survey or "one of the best" if more than one modality was checked.

\section{Statistical analysis}

Frequencies of residents' answers were calculated as percentages according to each modality and given clinical setting. For overall evaluation of the perception of modalities, all type of answers, including the "single best" and "one of the best", were taken into account.

\section{RESULTS}

\section{Neoplasm \\ Brain and spine}

MRI was considered one of the best imaging modalities to evaluate for neoplasm of brain by $26 / 27$ of residents, and as the single best method by $25 / 27$ of resi- dents. PET and CT were also cited as one of the best imaging modalities by $2 / 27$ and $1 / 27$ of residents, respectively. All residents from Univ A and Univ C programs described MR as the single best imaging modality to evaluate for neoplasm of the brain. MRI was also chosen as the single best imaging modality by $4 / 5$ of residents from Univ B program, while $1 / 5$ resident chose CT and PET as one of the best imaging modalities. While 13/14 residents from Univ $\mathrm{D}$ described MRI as the single best imaging modality, the remaining 1/14 described MRI and PET as one of the best imaging modalities in this clinical setting (Table 1).

All 27/27 residents, comprising all four programs, found MRI the single best imaging modality to investigate neoplasm of spine (Table 1).

\section{Lungs}

To investigate neoplasm of lung, 24/27 of residents have considered $\mathrm{CT}$ as one of the best imaging modalities, whereas 13/27 of residents have considered CT as the single best imaging modality. PET was considered as one of the best imaging modalities by $10 / 27$ of residents and the single best imaging modality by $3 / 27$ of residents. CT was the most frequent imaging modality chosen in all four programs to evaluate lung neoplasm, followed by PET. Table 1 presents detailed data based on imaging modalities and institutions.

\section{Abdomen (general)}

Overall, MRI was considered one of the best imaging modalities to evaluate abdominal neoplasm in general by 19/27 of residents. CT and PET were also considered as one of the best imaging modalities by $15 /$ 27 and 6/27 of residents, respectively. MRI was the most frequent imaging modality chosen at programs A and D, followed by CT. Table 1 presents detailed data based on imaging modalities and institutions.

When asked to evaluate for neoplasm in a specific abdominal organ, MRI was chosen as one of the best imaging modalities to evaluate for liver by $26 / 27$ of residents, for pancreas by $21 / 27$ of residents, and for kidneys by 19/27 of residents, considering all four programs. Table 1 presents detailed data based on imaging modalities and institutions. 
Table 1 Distribution of residents' answers relative to which is the best imaging modality to evaluate for neoplasm by organ or system, and by residency program.

\begin{tabular}{|c|c|c|c|c|c|c|}
\hline & \multirow[b]{2}{*}{ Residency program } & \multicolumn{5}{|c|}{ Imaging modalities } \\
\hline & & MR (\%) & CT (\%) & US (\%) & PET (\%) & X-ray (\%) \\
\hline \multirow[t]{5}{*}{ Brain } & Univ A & 6/6 (100.0) & $0 / 6(0.0)$ & $0 / 6(0.0)$ & 0/6 (0.0) & 0/6 (0.0) \\
\hline & Univ B & $4 / 5(80.0)$ & $1 / 5(20.0)$ & $0 / 5(0.0)$ & $1 / 5(20.0)$ & $0 / 5(0.0)$ \\
\hline & Univ C & $2 / 2(100.0)$ & 0/2 (0.0) & 0/2 (0.0) & 0/2 (0.0) & 0/2 (0.0) \\
\hline & Univ D & $14 / 14(100.0)$ & $0 / 14(0.0)$ & 0/14 (0.0) & $1 / 14(7.1)$ & 0/14 (0.0) \\
\hline & Total & 26/27 (96.3) & $1 / 27$ & 0/27 (0.0) & $2 / 27 \quad(7.4)$ & $0 / 27 \quad(0.0)$ \\
\hline \multirow[t]{5}{*}{ Spine } & Univ A & 6/6 (100.0) & 0/6 (0.0) & $0 / 6(0.0)$ & 0/6 (0.0) & 0/6 (0.0) \\
\hline & Univ B & $5 / 5(100.0)$ & $0 / 5(0.0)$ & $0 / 5(0.0)$ & $0 / 5(0.0)$ & 0/5 (0.0) \\
\hline & Univ C & $2 / 2(100.0)$ & 0/2 (0.0) & $0 / 2(0.0)$ & 0/2 (0.0) & 0/2 (0.0) \\
\hline & Univ D & $14 / 14(100.0)$ & 0/14 (0.0) & 0/14 (0.0) & 0/14 (0.0) & 0/14 (0.0) \\
\hline & Total & $27 / 27 \quad(100.0)$ & $0 / 27 \quad(0.0)$ & $0 / 27 \quad(0.0)$ & 0/27 (0.0) & 0/27 (0.0) \\
\hline \multirow[t]{5}{*}{ Lungs } & Univ A & 0/6 (0.0) & 6/6 (100.0) & 0/6 (0.0) & $3 / 6(50.0)$ & 0/6 (0.0) \\
\hline & Univ B & $0 / 5(0.0)$ & 4/5 (80.0) & $0 / 5(0.0)$ & $2 / 5(40.0)$ & 0/5 (0.0) \\
\hline & Univ C & $0 / 2(0.0)$ & $2 / 2(100.0)$ & $0 / 2(0.0)$ & 0/2 (0.0) & 0/2 (0.0) \\
\hline & Univ D & 0/14 (0.0) & $12 / 14(85.7)$ & 0/14 (0.0) & 9/14 (64.3) & 0/14 (0.0) \\
\hline & Total & $0 / 27 \quad(0.0)$ & 24/27 (88.9) & $0 / 27(0.0)$ & $14 / 27$ (51.9) & 0/27 (0.0) \\
\hline \multirow[t]{5}{*}{ Abdomen (general) } & Univ $\mathrm{A}$ & $4 / 6(66.7)$ & $3 / 6(50.0)$ & $0 / 6(0.0)$ & $1 / 6(16.7)$ & 0/6 (0.0) \\
\hline & Univ B & $2 / 5(40.0)$ & $3 / 5(60.0)$ & $0 / 5(0.0)$ & $1 / 5(20.0)$ & 0/5 (0.0) \\
\hline & Univ C & $2 / 2(100.0)$ & $2 / 2(100.0)$ & $0 / 2(0.0)$ & 0/2 (0.0) & 0/2 (0.0) \\
\hline & Univ D & 11/14 (78.6) & $7 / 14(50.0)$ & 0/14 (0.0) & 4/14 (28.6) & $0 / 14(0.0)$ \\
\hline & Total & 19/27 (70.4) & $15 / 27(55.6)$ & $0 / 27 \quad(0.0)$ & $6 / 27(22.2)$ & $0 / 27 \quad(0.0)$ \\
\hline \multirow[t]{5}{*}{ Liver } & Univ A & 6/6 (100.0) & $0 / 6(0.0)$ & $0 / 6(0.0)$ & $0 / 6(0.0)$ & 0/6 (0.0) \\
\hline & Univ B & $5 / 5(100.0)$ & $1 / 5(20.0)$ & $0 / 5(0.0)$ & $0 / 5(0.0)$ & 0/5 (0.0) \\
\hline & Univ C & $2 / 2(100.0)$ & $0 / 2(0.0)$ & 0/2 (0.0) & $0 / 2(0.0)$ & 0/2 (0.0) \\
\hline & Univ D & 13/14 (92.9) & $1 / 14(7.1)$ & 0/14 (0.0) & 1/14 (7.1) & 0/14 (0.0) \\
\hline & Total & 26/27 (96.3) & $2 / 27 \quad(7.4)$ & $0 / 27 \quad(0.0)$ & $1 / 27(3.7)$ & 0/27 (0.0) \\
\hline \multirow[t]{5}{*}{ Pancreas } & Univ A & 6/6 (100.0) & 1/6 (16.7) & $0 / 6(0.0)$ & $0 / 6(0.0)$ & 0/6 (0.0) \\
\hline & Univ B & $2 / 5(40.0)$ & 4/5 (80.0) & 0/5 (0.0) & 1/5 (20.0) & 0/5 (0.0) \\
\hline & Univ C & $1 / 2(50.0)$ & $2 / 2(100.0)$ & $0 / 2(0.0)$ & 0/2 (0.0) & 0/2 (0.0) \\
\hline & Univ D & $12 / 14(85.7)$ & 4/14 (28.6) & 0/14 (0.0) & 0/14 (0.0) & 0/14 (0.0) \\
\hline & Total & 21/27 (77.8) & $11 / 27 \quad(40.7)$ & $0 / 27 \quad(0.0)$ & $1 / 27 \quad(3.7)$ & 0/27 (0.0) \\
\hline \multirow[t]{5}{*}{ Kidneys } & Univ A & $5 / 6(83.3)$ & 4/6 (66.7) & $0 / 6(0.0)$ & $0 / 6(0.0)$ & 0/6 (0.0) \\
\hline & Univ B & $3 / 5(60.0)$ & $4 / 5(80.0)$ & $0 / 5(0.0)$ & $0 / 5(0.0)$ & 0/5 (0.0) \\
\hline & Univ C & $1 / 2(50.0)$ & $1 / 2(50.0)$ & $0 / 2(0.0)$ & 0/2 (0.0) & 0/2 (0.0) \\
\hline & Univ D & 10/14 (71.4) & 8/14 (57.1) & 2/14 (14.3) & $0 / 14(0.0)$ & $0 / 14(0.0)$ \\
\hline & Total & 19/27 (70.3) & 17/27 (63.0) & $2 / 27(7.4)$ & $0 / 27 \quad(0.0)$ & $0 / 27 \quad(0.0)$ \\
\hline \multirow[t]{5}{*}{ Muscuoskeletal system } & Univ A & $5 / 6(83.3)$ & $0 / 6(0.0)$ & $0 / 6(0.0)$ & $0 / 6(0.0)$ & $3 / 6(50.0)$ \\
\hline & Univ B & $3 / 5(60.0)$ & $0 / 5(0.0)$ & $0 / 5(0.0)$ & $1 / 5(20.0)$ & $2 / 5(40.0)$ \\
\hline & Univ C & $0 / 2(0.0)$ & $0 / 2(0.0)$ & $0 / 2(0.0)$ & 0/2 (0.0) & $2 / 2(100.0)$ \\
\hline & Univ D & 9/14 (64.3) & 4/14 (28.6) & $0 / 14(0.0)$ & 1/14 (7.1) & $6 / 14(42.9)$ \\
\hline & Total & $17 / 27 \quad(63)$ & 4/27 (14.8) & 0/27 (0.0) & $2 / 27 \quad(7.4)$ & $13 / 27(48.1)$ \\
\hline
\end{tabular}

\section{Musculoskeletal system}

To investigate musculoskeletal neoplasm, MR was chosen as one of the best imaging modalities by $17 / 27$ of residents, whereas $\mathrm{x}$-ray, CT and PET were also chosen by $13 / 27,4 / 27$, and $2 / 27$ of residents, respectively. See Table 1 for data subdivided by institutions.

\section{Trauma}

\section{Brain and spine}

Overall, CT was chosen as one of the best imaging modalities to investigate brain trauma by all residents. All residents from Univ A and Univ C programs chose CT as the single best imaging modality to evaluate brain trauma. At Univ B and Univ D residency programs, MR was also considered by $1 / 5$ and $3 / 14$ of residents (Table 2).

To investigate spinal trauma, CT was chosen one of the best imaging modalities by $25 / 27$ of residents, while MR and x-ray were also considered by $10 / 27$ and $1 / 27$ of residents, respectively. See Table 2 for data subdivided by institutions. 
Table 2 Distribution of residents' answers relative to which is the best imaging modality to evaluate for trauma by organ or system, and by residency program.

\begin{tabular}{|c|c|c|c|c|c|c|}
\hline & \multirow[b]{2}{*}{ Residency program } & \multicolumn{5}{|c|}{ Imaging modalities } \\
\hline & & MR (\%) & CT (\%) & US (\%) & PET (\%) & X-ray (\%) \\
\hline \multirow[t]{5}{*}{ Brain } & Univ A & 0/6 (0.0) & 6/6 (100.0) & $0 / 6(0.0)$ & 0/6 (0.0) & 0/6 (0.0) \\
\hline & Univ B & $1 / 5(20.0)$ & $5 / 5(100.0)$ & $0 / 5(0.0)$ & $0 / 5(0.0)$ & $0 / 5(0.0)$ \\
\hline & Univ C & $0 / 2(0.0)$ & $2 / 2(100.0)$ & $0 / 2(0.0)$ & $0 / 2(0.0)$ & $0 / 2(0.0)$ \\
\hline & Univ D & 3/14 (21.4) & $14 / 14(100.0)$ & 0/14 (0.0) & $0 / 14(0.0)$ & $0 / 14(0.0)$ \\
\hline & Total & 4/27 (14.8) & $27 / 27(100.0)$ & 0/27 (0.0) & $0 / 27(0.0)$ & $0 / 27(0.0)$ \\
\hline \multirow[t]{5}{*}{ Spine } & Univ A & $3 / 6(50.0)$ & 6/6 (100.0) & 0/6 (0.0) & $0 / 6(0.0)$ & $0 / 6(0.0)$ \\
\hline & Univ B & $2 / 5(40.0)$ & $5 / 5(100.0)$ & $0 / 5(0.0)$ & $0 / 5(0.0)$ & 0/5 (0.0) \\
\hline & Univ C & $1 / 2(50.0)$ & $1 / 2(50.0)$ & $0 / 2(0.0)$ & 0/2 (0.0) & 0/2 (0.0) \\
\hline & Univ D & 4/14 (28.6) & 13/14 (92.9) & 0/14 (0.0) & $0 / 14(0.0)$ & $1 / 14(7.1)$ \\
\hline & Total & $10 / 27(37.0)$ & 25/27 (92.6) & 0/27 (0.0) & $0 / 27(0.0)$ & $1 / 27(3.7)$ \\
\hline \multirow[t]{5}{*}{ Chest } & Univ $\mathrm{A}$ & 0/0 (0.0) & $5 / 6(83.3)$ & 0/0 (0.0) & 0/0 (0.0) & $1 / 6(16.7)$ \\
\hline & Univ B & $0 / 5(0.0)$ & $5 / 5(100.0)$ & 0/5 (0.0) & $0 / 5(0.0)$ & $0 / 5(0.0)$ \\
\hline & Univ C & $0 / 2(0.0)$ & $2 / 2(100.0)$ & $0 / 2(0.0)$ & $0 / 2(0.0)$ & 0/2 (0.0) \\
\hline & Univ D & $1 / 14(7.1)$ & $14 / 14(100.0)$ & 0/14 (0.0) & $0 / 14(0.0)$ & $1 / 14(7.1)$ \\
\hline & Total & $1 / 278(3.7)$ & 26/27 (96.3) & 0/27 (0.0) & $0 / 27(0.0)$ & $2 / 27(7.4)$ \\
\hline \multirow[t]{5}{*}{ Abdomen (general) } & Univ $\mathrm{A}$ & 0/6 (0.0) & 6/6 (100.0) & 0/6 (0.0) & $0 / 6(0.0)$ & 0/6 (0.0) \\
\hline & Univ B & $0 / 5(0.0)$ & $5 / 5(100.0)$ & $0 / 5(0.0)$ & $0 / 5(0.0)$ & $0 / 5(0.0)$ \\
\hline & Univ C & 0/2 (0.0) & 0/2 (0.0) & $2 / 2(100.0)$ & $0 / 2(0.0)$ & 0/2 (0.0) \\
\hline & Univ D & $0 / 14(0.0)$ & $14 / 14(100.0)$ & $1 / 14(7.1)$ & $0 / 14(0.0)$ & $0 / 14(0.0)$ \\
\hline & Total & $0 / 27 \quad(0.0)$ & 25/27 (92.6) & $3 / 27(11.1)$ & $0 / 27(0.0)$ & $0 / 27(0.0)$ \\
\hline \multirow[t]{5}{*}{ Liver } & Univ A & 0/6 (0.0) & 6/6 (100.0) & 0/6 (0.0) & 0/6 (0.0) & 0/6 (0.0) \\
\hline & Univ B & $0 / 5(0.0)$ & $5 / 5(100.0)$ & 0/5 (0.0) & $0 / 5(0.0)$ & $0 / 5(0.0)$ \\
\hline & Univ C & $0 / 2(0.0)$ & $2 / 2(100.0)$ & 0/2 (0.0) & $0 / 2(0.0)$ & 0/2 (0.0) \\
\hline & Univ D & 0/14 (0.0) & 13/14 (92.9) & $2 / 14$ & $0 / 14(0.0)$ & $0 / 14(0.0)$ \\
\hline & Total & $0 / 27(0.0)$ & 26/27 (96.3) & $2 / 27(7.4)$ & $0 / 27(0.0)$ & $0 / 27(0.0)$ \\
\hline \multirow[t]{5}{*}{ Pancreas } & Univ A & 0/6 (0.0) & 6/6 (100.0) & $0 / 6(0.0)$ & $0 / 6(0.0)$ & 0/6 (0.0) \\
\hline & Univ B & $0 / 5(0.0)$ & $5 / 5(100.0)$ & $0 / 5(0.0)$ & $0 / 5(0.0)$ & $0 / 5(0.0)$ \\
\hline & Univ C & $0 / 2(0.0)$ & $2 / 2(100.0)$ & 0/2 (0.0) & $0 / 2(0.0)$ & $0 / 2(0.0)$ \\
\hline & Univ D & 3/14 (21.4) & $12 / 14(85.7)$ & 0/14 (0.0) & $0 / 14(0.0)$ & $0 / 14(0.0)$ \\
\hline & Total & $3 / 27(11.1)$ & 25/27 (92.6) & 0/27 (0.0) & $0 / 27(0.0)$ & $0 / 27(0.0)$ \\
\hline \multirow[t]{5}{*}{ Kidneys } & Univ A & 0/6 (0.0) & 6/6 (100.0) & 0/6 (0.0) & $0 / 6(0.0)$ & 0/6 (0.0) \\
\hline & Univ B & $0 / 5(0.0)$ & $5 / 5(100.0)$ & 0/5 (0.0) & 0/5 (0.0) & 0/5 (0.0) \\
\hline & Univ C & $0 / 2(0.0)$ & $2 / 2(100.0)$ & 0/2 (0.0) & $0 / 2(0.0)$ & 0/2 (0.0) \\
\hline & Univ D & $1 / 14(7.1)$ & $14 / 14(100.0)$ & $1 / 14(7.1)$ & $0 / 14(0.0)$ & $0 / 14(0.0)$ \\
\hline & Total & $1 / 27(3.7)$ & $27 / 27(100.0)$ & $1 / 27$ & $0 / 27(0.0)$ & $0 / 27(0.0)$ \\
\hline \multirow{5}{*}{$\begin{array}{l}\text { Musculoskeletal system } \\
\text { sports injury }\end{array}$} & Univ A & 6/6 (100.0) & 0/6 (0.0) & 0/6 (0.0) & 0/6 (0.0) & $1 / 6(16.7)$ \\
\hline & Univ B & $5 / 5(100.0)$ & $0 / 5(0.0)$ & $0 / 5(0.0)$ & 0/5 (0.0) & 0/5 (0.0) \\
\hline & Univ C & $2 / 2(100.0)$ & 0/2 (0.0) & 0/2 (0.0) & $0 / 2(0.0)$ & 0/2 (0.0) \\
\hline & Univ D & $13 / 14(92.9)$ & $2 / 14(14.3)$ & 0/14 (0.0) & $0 / 14(0.0)$ & $0 / 14(0.0)$ \\
\hline & Total & $26 / 27$ (96.3) & $2 / 27(7.4)$ & 0/27 (0.0) & $0 / 27(0.0)$ & $1 / 27$ \\
\hline \multirow{5}{*}{$\begin{array}{l}\text { Musculoskeltal system } \\
\text { major trauma }\end{array}$} & Univ A & 0/6 (0.0) & 5/6 (83.3) & 0/6 (0.0) & $0 / 6(0.0)$ & $3 / 6(50.0)$ \\
\hline & Univ B & $1 / 5(20.0)$ & $2 / 5(40.0)$ & 0/5 (0.0) & $0 / 5(0.0)$ & $3 / 5(60.0)$ \\
\hline & Univ C & 0/2 (0.0) & 0/2 (0.0) & 0/2 (0.0) & $0 / 2(0.0)$ & $2 / 2(100.0)$ \\
\hline & Univ D & $1 / 14(7.1)$ & 13/14 (92.9) & 0/14 (0.0) & $0 / 14(0.0)$ & $4 / 14(28.6)$ \\
\hline & Total & $2 / 27(7.4)$ & 20/27 (74.1) & 0/27 (0.0) & $0 / 27(0.0)$ & $12 / 27(44.4$ \\
\hline
\end{tabular}




\section{Chest}

Overall, CT was chosen as one of the best imaging modalities to evaluate for chest trauma by $26 / 27$ of residents, while $x$-ray and MR were also considered by $2 / 27$ and $1 / 27$ of residents, respectively. See Table 2 for data subdivided by institutions.

\section{Abdomen (general)}

CT was chosen one of the best imaging modalities to evaluate abdominal trauma in general by $25 / 27$ of residents, and the single best imaging modality by $24 / 27$ of residents (including all residents from Univ A and Univ B programs). See Table 2 for data subdivided by institutions.

When asked to evaluate for trauma in a specific abdominal organ, CT was chosen as one of the best imaging modalities to evaluate for liver trauma by $26 / 27$ of residents, for pancreas trauma by $25 / 27$ of residents, and for kidney trauma by $27 / 27$ of residents, considering residents from all four programs. See Table 2 for data subdivided by institutions.

\section{Musculoskeletal system}

In evaluation of sports injury, MR was chosen as one of the best imaging modalities by $26 / 27$ of residents and as the single best imaging modality by $24 / 27$ of residents. X-ray and CT were also considered by $1 / 27$ and $2 / 27$ of residents, respectively. See Table 2 for data subdivided by institutions.

CT was chosen as one of the best imaging modalities to evaluate for major musculoskeletal trauma by 20/27 of residents. $\mathrm{X}$-ray and MR were also considered by $12 /$ 27 and $2 / 27$ of residents, respectively. See Table 2 for data subdivided by institutions.

\section{DISCUSSION}

The intention of this study was to sample residents' perception of what the best exam is for neoplasm and trauma investigation rather than to determine what the best study is per se. This approach seems appropriate when evaluating medical education as the 4th year graduating residents have a full overview of the imaging modalities' capabilities, of the diagnosis process, of their institutions' policies and protocols, as well as a full overview of the literature. In this way, we believe that a survey of residents' perception was an appropriate approach to assess institution training and variability in training. We elected to test residents' perception in two different clinical settings, neoplasm and trauma, as they are two of the largest categories requiring imaging investigation. We opted not to subdivide these two broad categories further because of the pilot nature of the study. The administrator for the residency program distributed the survey, and the surveys were anonymously completed in order to minimize any possible bias of response selection. Perhaps the most challenging aspect of the study was to get $100 \%$ completion rate of the surveys, which was also considered essential to minimize bias.

Overall, the residents from all programs agreed that MRI was one of the best imaging modalities to evaluate for brain and spinal neoplasm, reporting $96.3 \%$ and $100 \%$, respectively. This finding concurs with the ACR appropriateness criteria. There is no specific appropriateness criteria for brain neoplasm published by ACR, but from the nine variants of the appropriateness criteria for headache, eight have MRI with the highest rating, although four of them show CT with the same rating as $\mathrm{MRI}^{(6)}$. In its variant 3 for low back pain (suspicion for neoplasm, infection, and immunosuppression) the ACR rates MRI as the first choice imaging modality ${ }^{(7)}$. The data reflects the established role of MRI in the imaging evaluation of central nervous system neoplasm. Additionally MRI provides comprehensive evaluation, including anatomical, functional and metabolic ${ }^{(\mathbf{8})}$.

The residents' perception for the best imaging exam to evaluate for lung neoplasm was that CT and PET were chosen by $88.9 \%$ and $51.9 \%$ of residents, respectively. This reflects the ability of CT to detect and stage lung neoplasm. The fact that a relatively large percentage of residents also considered PET as an option to evaluate for lung neoplasm can be explained by: 1) the increasing number of PET/CT exams compared to PET alone, which also reflects the role of CT to evaluate for lung neoplasm; and 2) the growing evidence that metabolic imaging can provide useful prognosis prediction, assess tumor response to treatment, and facilitate treatment planning by detecting sites of mediastinal and metastatic disease $\mathrm{e}^{(\mathbf{9})}$. Nonetheless, there was a small discordance between residents from different programs regarding the choice of PET to evaluate for lung neoplasm which may represent the inclusion of an evolving modality into clinical practice.

In contrast to the high level of agreement that MRI is the best modality to evaluate CNS neoplasm and CT is the best to evaluate for lung neoplasm, there was less concordance between residents as to the optimal imaging modality to evaluate for abdominal neoplasm in general. Considering all four residency programs, while $96.3 \%$ to $100 \%$ of residents chose MRI as one of the best imaging modalities for brain and spine neoplasm evaluation only $70.4 \%$ of residents chose it to evaluate for abdominal neoplasm in general. Interestingly, MRI was chosen as one of the best imaging modalities by $96.3 \%$ of residents considering all four programs to evaluate for liver neoplasm. Our impression is that this reflects the large body of literature and institutional experience with MRI of the liver, whereas organs with lesser amounts of literature, kidney and pancreas, had more heterogeneous distribution of reporting.

There was a substantial discrepancy related to the resident perception of how to investigate musculoskeletal neoplasm by imaging. This may in part reflect the brevity of the survey. Nonetheless, MR and $\mathrm{x}$ ray were considered the best imaging modalities to evaluate for musculoskeletal neoplasm by $63 \%$ and $48.1 \%$ of residents, which concurs with the ACR appropriateness criteria for bone tumors ${ }^{(10)}$.

The overall perception of the optimal imaging modality to evaluate for trauma, independent of the organ system, was more homogeneous. This shows that CT has a major role in trauma, with the exception of sports injury in which MRI was chosen as the best imaging modality, and by major musculoskeletal trauma where plain films were chosen as the best imaging modality by most of the residents. A major single item of discordance occurred in general abdominal trauma evaluation, in which all residents from Univ $\mathrm{C}$ described ultrasound as the best imaging modality. This may be 
accounted for on the basis of regional difference in practice, the residents' perception of type of trauma, for example in blunt abdominal trauma, ultrasound can be considered as the first imaging choice to screen for hemoperitoneum in hemodynamically unstable patients ${ }^{(\mathbf{1 1})}$, and by the small number of residents in that program.

In distinction to our training programs in which almost $100 \%$ of residents considered MRI to be the best method to investigate liver masses (compared to $96.3 \%$ of residents who considered this to be the case for brain neoplasm), national surveys report that a minority of liver examinations are performed by MRI with the majority performed by CT (personal communication, Alberto Spinazzi, MD). Since we did not survey the general radiology community, we can only speculate on the possible causes for the discordance. Included in this would be inadequate training or experience by practicing radiologists, limited time on MRI equipment, and perhaps insufficient concern of the potential harmful effects of radiation.

This survey was designed to be primarily descriptive; however several assumptions were made which could result in error. It was assumed that all residents received optimal neuroimaging, chest, body and musculoskeletal training in regards to the roles of various imaging modalities. Also, there was no comparison between programs regarding number of interpretations by residents on different imaging modalities or on different organ systems during their rotations. Survey type research is notorious for being biased or selective. Surveys are generally completed by individuals who either have a complaint, or who want to curry favor. We attempted to eliminate these biases by having the residency program coordinator send out and receive the forms, having the forms anonymously filled out, and by achieving $100 \%$ capture of the individuals who the survey is intended for. The limited number of institutions surveyed, as well as the different number of residents by program may also introduce errors due to small sample size. It would be interesting to include more sites by US regions which would be more representative of the US radiology training, as it would allow a study of the impact of hospital size, academic institution affiliation and geography in residency programs ${ }^{(5)}$. As a pilot study we understand that the results reflect a very small sample of the country. In the setting of a larger study it will be challenging to obtain $100 \%$ capture, as we were able to do. It would be more challenging yet but quite interesting to study US radiology residents' perception compared to radiology residents' perception from another countries.

This study may point the direction to more large scale surveys of many or all university institutions, eventually to ensure a high level of learning and quality assurance among graduating residents. Such a large scale survey may be difficult to set up, but once established may provide a useful mechanism to evaluate quality in training. Such a survey may also be interesting or important for individual institutions to see how they compare to other institutions on the national average. It would also be interesting to include comparisons with staff attending radiologists and specialists in the future surveys. One goal we believe we achieved is to show residents' perception is a measurable variable which, in our view, is important and useful in radiology programs evaluation as it compares to the current radiology practice around the country.

In our study, we observed that 4th year radiology residents from multiple residency programs in different regions of the US followed ACR guidelines, either deliberately or through training provided at their program. This contrasts a published study in which pediatric residents in various stages of training did not perform well in appropriateness of radiology test ordering $^{(\mathbf{1 2})}$. As also contrasts with a more recently published study in which house-staff clinicians did not change their CT scan ordering patterns after being educated by radiologists about the potential effects of radiation produced by $\mathrm{CT}^{(\mathbf{1 3})}$. This suggests that the role of future radiologists will continue to involve education of their col- leagues in finding the appropriate study to evaluate their clinical question.

The summary of the findings in this study show that residents in four university practices reported that for the investigation of neoplasm, MRI may be the best tool in the brain, spine, abdomen, and musculoskeletal system, and CT may be the best tool in the chest. For the investigation of trauma, CT may be the best tool in the investigation of the brain, spine, and abdomen, plain X-rays for major musculoskeletal trauma and MRI for sports injury.

\section{REFERENCES}

1. Dixon AK. Evidence-based diagnostic radiology. Lancet. 1997;350:509-12.

2. Center for Devices and Radiological Health. Volume 2006: U. S. Food and Drug Administration Web Site. Available from: http://www.fda.gov/ cdrh/index.html.

3. American College of Radiology. Volume 2006: ACR Web Site. Available from: http://www.acr. org/s_acr/index.asp.

4. ACR Appropriateness Criteria ${ }^{\circledR}$ - Background and Development. Volume 2006: ACR Web Site. Available from: http://www.acr.org/s_acr/bin. asp?CID $=1847 \& D I D=16124 \& D O C=$ FILE.PDF

5. Green GE, Forman HP. Residency training as technology matures a survey of radiology residents' training experiences. Acad Radiol. 2006; 13:874-9.

6. Jordan JE, Seidenwurm DJ, Davis PC, et al. Headache. ACR Appropriateness Criteria ${ }^{\circledR} 2006$ : American College of Radiology Web site. Available from: www.acr.org.; 2006.

7. Bradley Jr WG, Seidenwurm DJ, Brunberg JA, et al. Low back pain. ACR Appropriateness Criteria® 2005: American College of Radiology Web site. Available from www.acr.org.; 2005.

8. Cha S. Update on brain tumor imaging: from anatomy to physiology. AJNR Am J Neuroradiol. 2006;27:475-87

9. Bruzzi JF, Munden RF. PET/CT imaging of lung cancer. J Thorac Imaging. 2006;21:123-36.

10. Morrison WB, Dalinka MK, Daffner RH, et al Bone tumors. ACR Appropriateness Criteria ${ }^{\circledR}$ 2005: American College of Radiology Web site. Available from: www.acr.org.; 2005.

11. Shuman WP, Holtzman SR, Bree RL, et al. Blunt abdominal trauma. ACR Appropriateness Criteria ${ }^{\circledR}$ 2005: American College of Radiology Web site. Available from: www.acr.org.; 2005.

12. Hirschl DA, Ruzal-Shapiro C, Taragin BH. Online survey of radiologic ordering practices by pediatric trainees. J Am Coll Radiol. 2010;7:360-3.

13. Horowitz JM, Yaghmai V, Miller FH, et al. Will $\mathrm{CT}$ ordering practices change if we educate residents about the potential effects of radiation exposure? Experience at a large academic medical center. Acad Radiol. 2011. 